Article

\title{
Environmental Impact of Construction Products on Aquatic Systems-Principles of an Integrated Source-Path-Target Concept
}

\author{
Ute Schoknecht $^{1, *}$, Olaf Tietje ${ }^{2}$, Nicole Borho ${ }^{3}$, Michael Burkhardt ${ }^{4}{ }^{D}$, Mirko Rohr ${ }^{4}$, Anya Vollpracht ${ }^{5}$ \\ and Lia Weiler ${ }^{5}$ (D)
}

check for

updates

Citation: Schoknecht, U.; Tietje, O.; Borho, N.; Burkhardt, M.; Rohr, M.; Vollpracht, A.; Weiler, L.

Environmental Impact of Construction Products on Aquatic Systems-Principles of an Integrated Source-Path-Target Concept. Water 2022, 14, 228. https://doi.org/ $10.3390 / w 14020228$

Academic Editor: Francesco De Paola

Received: 30 November 2021

Accepted: 1 January 2022

Published: 13 January 2022

Publisher's Note: MDPI stays neutral with regard to jurisdictional claims in published maps and institutional affiliations.

Copyright: (C) 2022 by the authors. Licensee MDPI, Basel, Switzerland. This article is an open access article distributed under the terms and conditions of the Creative Commons Attribution (CC BY) license (https:// creativecommons.org/licenses/by/ $4.0 /)$.
1 Federal Institute for Materials Research and Testing (BAM), Unter den Eichen 87, 12205 Berlin, Germany

2 Unit for Mathematics and Natural Science, Eastern Switzerland University of Applied Sciences, Oberseestrasse 10, 8640 Rapperswil, Switzerland; olaf.tietje@ost.ch

3 Dr. Robert-Murjahn-Institute GmbH, Industriestraße 12, 64372 Ober-Ramstadt, Germany; nicole.borho@dr-rmi.de

4 Institute of Environmental and Process Engineering (UMTEC), Eastern Switzerland University of Applied Sciences, Oberseestrasse 10, 8640 Rapperswil, Switzerland; michael.burkhardt@ost.ch (M.B.); mirko.rohr@ost.ch (M.R.)

5 Institute of Building Materials Research (ibac), RWTH Aachen University, Schinkelstraße 3, 52062 Aachen, Germany; vollpracht@ibac.rwth-aachen.de (A.V.); weiler@ibac.rwth-aachen.de (L.W.)

* Correspondence: ute.schoknecht@bam.de

\begin{abstract}
Buildings exposed to water can release undesirable substances which, once transported to environmental compartments, may cause unwanted effects. These exposure pathways need to be investigated and included in risk assessments to safeguard water quality and promote the sustainability of construction materials. The applied materials, exposure conditions, distribution routes and resilience of receiving compartments vary considerably. This demonstrates the need for a consistent concept that integrates knowledge of emission sources, leaching processes, transport pathways, and effects on targets. Such a consistent concept can serve as the basis for environmental risk assessment for several scenarios using experimentally determined emissions. Typically, a source-path-target concept integrates data from standardized leaching tests and models to describe leaching processes, the distribution of substances in the environment and the occurrence of substances at different points of compliance. This article presents an integrated concept for assessing the environmental impact of construction products on aquatic systems and unravels currently existing gaps and necessary actions. This manuscript outlines a source-path-target concept applicable to a large variety of construction products. It is intended to highlight key elements of a holistic evaluation concept that could assist authorities in developing procedures for environmental risk assessments and mitigation measures and identifying knowledge gaps.
\end{abstract}

Keywords: construction products; environmental impact; assessment; concept

\section{Introduction: Concept for the Evaluation of the Environmental Impact of Construction Products}

Sustainable building includes the proactive use of environmentally friendly construction products with a low environmental footprint during production, service life and end of life.

The emission of substances from construction products due to water contact during service life has been demonstrated for various construction products and materials like treated wood [1], bituminous sheets [2,3], façades [4-6], fibre cement sheets [7], paints and textiles [8], anti-corrosion coatings [9], concrete [10,11], cement pastes [12], fire-retardant coatings [13], roof membranes [14] and roof paints [15]. These emissions can result in different organic and inorganic substances reaching surface waters, groundwater and soils 
which, depending on their properties and concentrations, may affect water quality and organisms [16-19].

The development of environmentally safe construction products is of importance to environmental agencies and regulators (see the box on European regulations), manufacturers, researchers, and end users. Therefore, regulations have been developed to assess and minimize harmful emissions from construction products. However, implementing these in practice is challenging for several reasons: (a) leaching processes and emissions patterns of substances are very complex and dynamic, (b) regulations encompass a wide variety of products and applications under different conditions across Europe and (c) decisions on the approval of construction products must be based on sound concepts.

An approach to risk assessments using model-based scenarios and leaching data is most promising and already common for certain products such as pesticides and certain biocides. Regulators often define scenarios that focus on specific environmental compartments. However, applying a source-path-target concept means both (1) to define scenarios, each of which includes the source, path and target aspect for a specific risk assessment and (2) to provide a comprehensive set of scenarios and evaluation rules.

Aspects of a source-path-target approach for construction products are already taken into account in some EU Member States, e.g., the Ersatzbaustoffverordnung (ordinance for substitute building materials) in Germany [20] and the 'Besluit Bodemkwaliteit' (Soil Quality Decree) in the Netherlands [21].

The source term of the scenario is described by the leaching behaviour of a substance from a construction product, preferably based on standardized laboratory leaching tests. These tests provide information on the intrinsic leaching properties of the material. Although standardized tests describe leaching processes as a simplified phenomenon, these offer a basis for estimating emissions in the field under the defined scenario conditions.

The path encompasses the transport of substances from the source to the environmental compartments. The path term is characterized using scenarios. For instance, field scenarios include parameters like the area of the application, the net infiltration rate, soil properties and stormwater discharge to surface waters. In an impact assessment for a specific site, the scenario conditions might be fine-tuned, e.g., to the local soil properties or weather conditions.

Targets are environmental compartments where leached substances can cause unwanted effects. Regulators establish points of compliance (e.g., $1 \mathrm{~m}$ below the soil surface) and the environmental criteria that must be met at these points, i.e., threshold concentration values. Often, these criteria are based on ecotoxicological assessments.

This manuscript outlines the cornerstones of an integrated approach for the assessment of emissions, from construction products to the environment. The approach is based on experiences from different disciplines like material and environmental sciences, mathematics and simulations addressing the leaching of substances from construction products into soil and surface water. This approach addresses dissolved inorganic and organic substances and ignores particles, particle-bound substances and microplastic. It mainly applies to construction products regulated by the Construction Products Regulation (CPR) [22], which are also affected by other European regulations (see Box 1).

The overview of existing information and regulations provided in this article indicates that essential information and tools are missing to fully implement such an integrated approach. This manuscript therefore identifies 'blind spots' required to do so. 
Box 1. European Regulations.

European Regulations Concerning Environmental Safety of Construction Products:

Construction Products Regulation (CPR, Regulation (EU) No 305/2011) [22]

Basic requirement No. 3: The construction works must be designed and built in such a way that they will, throughout their life cycle, not be a threat to the hygiene or health and safety of workers, occupants or neighbours, nor have an exceedingly high impact, over their entire life cycle, on the environmental quality or on the climate during their construction, use and demolition, ...

These requirements are to be included in European standards for mandated construction products and at least be reflected in European Environmental Products Declarations (EPDs) and CE marking.

Biocidal Products Regulation (BPR, Regulation (EU) No 528/2012) [23]

Marketing and the use of biocidal products require environmental risk assessments for biocidal products that are intended to be applied, for example, as preservatives in treated articles like paints for the following product types:

Product type 6: Preservatives for products during storage

Product type 7: Film preservatives

Product type 8: Wood preservatives

Product type 9: Fibre, leather, rubber and polymerised materials preservatives

Product type 10: Construction material preservatives

Registration, Evaluation, Authorisation and Restriction of Chemicals (REACH, Regulation (EC) No 1907/2006 [24]

The use of chemicals in construction products can be restricted. Substances of very high concern, e.g., persistent, bioaccumulative and toxic substances, are continuously added to a candidate list and must be authorized.

Water Framework Directive (Directive 2000/60/EC) [25]

The water policy of the European Community aims to preserve and improve the aquatic environment and includes measures that might influence civil works. Special attention is paid to prioritized substances.

Article 1-Purpose

The purpose of this Directive is to establish a framework for the protection of inland surface waters, transitional waters, coastal waters and groundwater which: ...

(c) aims at enhanced protection and improvement of the aquatic environment, inter alia, through specific measures for the progressive reduction of discharges, emissions and losses of priority substances and the cessation or phasing-out of discharges, emissions and losses of the priority hazardous substances

Article 11-Programme of measures

Member states ... may authorise, specifying the conditions for ... construction, civil engineering and building works and similar activities on, or in the ground which come into contact with groundwater...

The assessment of the environmental impact of construction products needs simplifications due to the huge variety of products and parameters. Nevertheless, a generic approach must reflect the most relevant processes and parameters based on data from field and laboratory tests.

The conceptual outline of the source-path-target concept is given in Figure 1. Three main activity fields were identified.

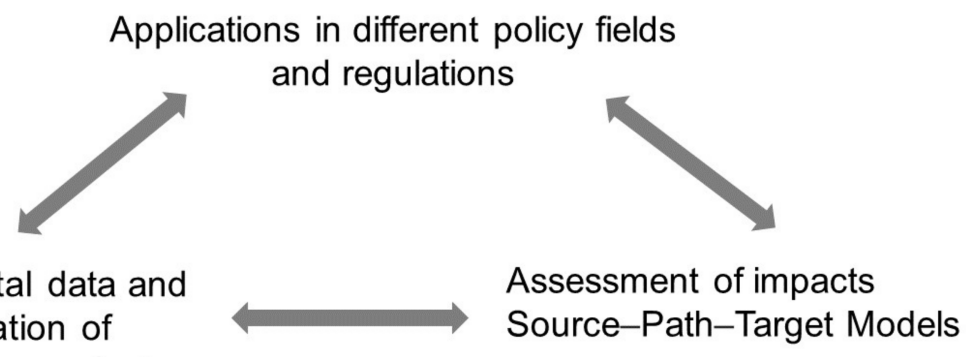

Experimental data and Source-Path-Target Models construction products

Figure 1. Outline of an integrated approach for construction products over service life. 


\subsection{Acquisition of Experimental Leaching Data, Preferably from Standardized Tests}

Leaching data are the basis for a harmonized approach. Reproducible laboratory tests are developed and standardized at a European level. Studies are mostly performed by manufacturers and researchers and used in standardization mandates.

\subsection{Impact Assessment}

The results of the standardized tests need to be translated into different practical release scenarios. Models are a common tool to perform this data abstraction. Typically, simulation models are closely linked to the tests and serve as a basis to describe the leaching behaviour and to identify the most relevant factors for the pathway to the compartments.

\subsection{Application in Policy Fields and Regulations}

The assessment combines estimates of environmental concentrations and requirements defined by regulators, manufacturers and product labels etc. It refers to the scientific background on the processes and validated models, enabling informed policy decisions.

The outline of an integrated approach presented in Figure 1 does not characterize a one-way dependency. The choices, value settings and policy requirements by different stakeholders clearly determine the required accuracy of the tests and the allowed degree of model simplifications. The outlined approach forms a sound basis for the harmonization of impact assessment and the development of (national) regulations for the application of construction materials. As this basis is similar for subjects belonging to different policy fields (e.g., construction materials, biocides and waste), the approach can lead to a more holistic method, that is consistent over these fields.

\section{Experimental Leaching Data of Construction Products}

The basic chemical and physical processes causing the leaching of substances from construction products are known [26]. Experimental data from leaching studies and the environmental occurrence of such substances have been published for numerous construction products. Material properties and test parameters that influence leaching processes under laboratory and outdoor test conditions have been investigated, e.g., UV degradation and water contact time [10,11,27-30]. Research has also been directed to the natural exposure conditions that determine emissions as well as the distribution and fate of emissions in urban environments [5,6,17,31].

Laboratory tests for construction products were developed by the Technical Committee CEN/TC 351 'Construction products: Assessment of release of dangerous substances. A set of horizontal leaching tests is intended to cover all construction products (prEN 16637:2021). This series of standards includes general guidance (part 1 [32]), the horizontal dynamic surface leaching test for monolithic construction products (part 2, 'DSLT' [33]) and the horizontal up-flow percolation test for granular construction products (part 3 [34]) The applicability of these leaching test methods and sensitivity towards test parameters were investigated in a robustness study of CEN/TC 351 WG 1 for several construction products [35]. Accompanying tests can provide the information required to transfer results obtained under laboratory conditions to field applications. Leaching tests that include intermittent wet and dry periods were developed for treated wood by CEN/TC 38 (CEN/TS 15119-1 [36]) and for architectural coatings by CEN/TC 139 (EN 16105 [37,38]) to reflect occasional water contact of construction products compared to permanent water contact in the DSLT. CEN/TC 38 defined a semi-field method to determine emissions from treated wood (CEN/TS 16663 [39]).

Examples for application of data from laboratory leaching tests [33,34,37] are:

1. Comparison of the leaching behaviour of construction products

2. Indication of the leaching potential of substances

3. Use as worst-case emission data from products, e.g., if under use conditions, lower emissions are expected 


\section{Input for estimation of emission using leaching models}

In general, laboratory tests describe leaching properties of materials under reproducible and controlled conditions limited to selected parameters like temperature, quality and amount of water, duration of water contact, next to sample preparation. However, substance release depends on additional factors and processes like varying dry-wet cycles and chemical transformation. Therefore, the basic information on leaching processes that is obtained from laboratory tests needs to be transferred into service life conditions.

As an example: The leaching of monolithic materials (e.g., concrete, bricks) is usually performed with a DSLT under continuously saturated conditions in the laboratory at

$20^{\circ} \mathrm{C}$. The test results need to be translated to real field conditions. A simplistic approach for translation is assuming a more realistic period of wet conditions in the field (e.g., $10 \%$ of the time) and assessing the average temperature in the field $\left(e . g ., 10^{\circ} \mathrm{C}\right)$. The corrected leaching test results are then the source term for the scenario calculations. However, it has to be considered that such a simplified approach may neglect relevant processes occurring in the field and therefore result in a significant underestimation of the environmental impact.

Tests to investigate the influence of $\mathrm{pH}$ on the leaching behaviour of substances have not been developed for construction products, as is the case for waste (EN 14429 [40] and 14997 [41]). So far, there is no agreement on UV degradation tests that can be applied to investigate the transformation of substances in relation to leaching.

In the best case, (a) the release under field conditions is studied, (b) these results are linked to the laboratory test results and (c) environmental exposure data for model validation are available. The lab/field validation provides a sound basis for any assessment framework, e.g., technical and policy choices.

No universal correlation exists between field and laboratory results neither according to the intermittent dipping test [37] nor to the DSLT (prEN 16637-2) [33]. The intermittent test is expected to cause a higher release of organic substances compared to leaching from construction products in the field. Organic substances from paints in laboratory leaching tests and field experiments are shown in Figure 2. The left graph shows laboratory experiments using three different batches of freshly prepared paint that resulted in only slightly different emission curves. In contrast to that, the emission curve of the outdoor experiment shown in the right graph runs irregularly and depends-among other parameters-on the amount of wind driven rain on the test specimens. In fact, façade panels, renders and coatings are exposed to dynamic weather conditions in contrast to constant conditions in the laboratory.
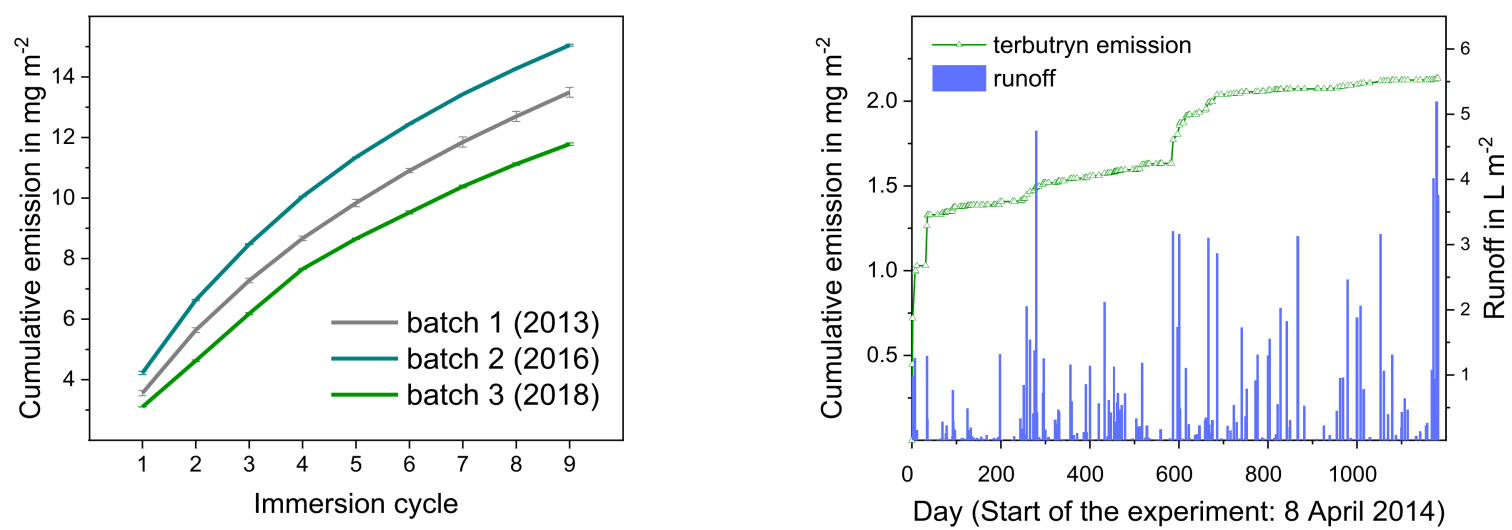

Figure 2. Emission of the biocidal active substance terbutryn from painted wood (1) in laboratory experiments according to EN 16105 [39] using three different batches of paint and (2) during an outdoor experiment (data from [27], completed by unpublished data). Error bars in the left graph indicate minimum and maximum values of parallel tests. 
For the leaching behaviour of inorganic constituents from concrete, plasters and renders, the DSLT does not necessarily deliver higher release compared with the field [42,43]. Figure 3 demonstrates the differences for arsenic, zinc and vanadium from concrete sheets tested in the laboratory and outdoors. The cumulative release over the testing time is plotted against the contact time, which refers to the testing time for the DSLT, and against the cumulative duration of the rain periods outdoor. As the DSLT is designed for diffusioncontrolled release and comparably high amounts of water are used, plotting against the amount of water seems not adequate [11]. Higher emissions of zinc and vanadium were observed in the DSLT (Figure 3b,c), whereas the release of arsenic was higher during the outdoor experiment (Figure 3a). Depending on test conditions (e.g., water contact time, water amount) and substance properties, the leaching tests describe different mechanisms associated with different emissions.
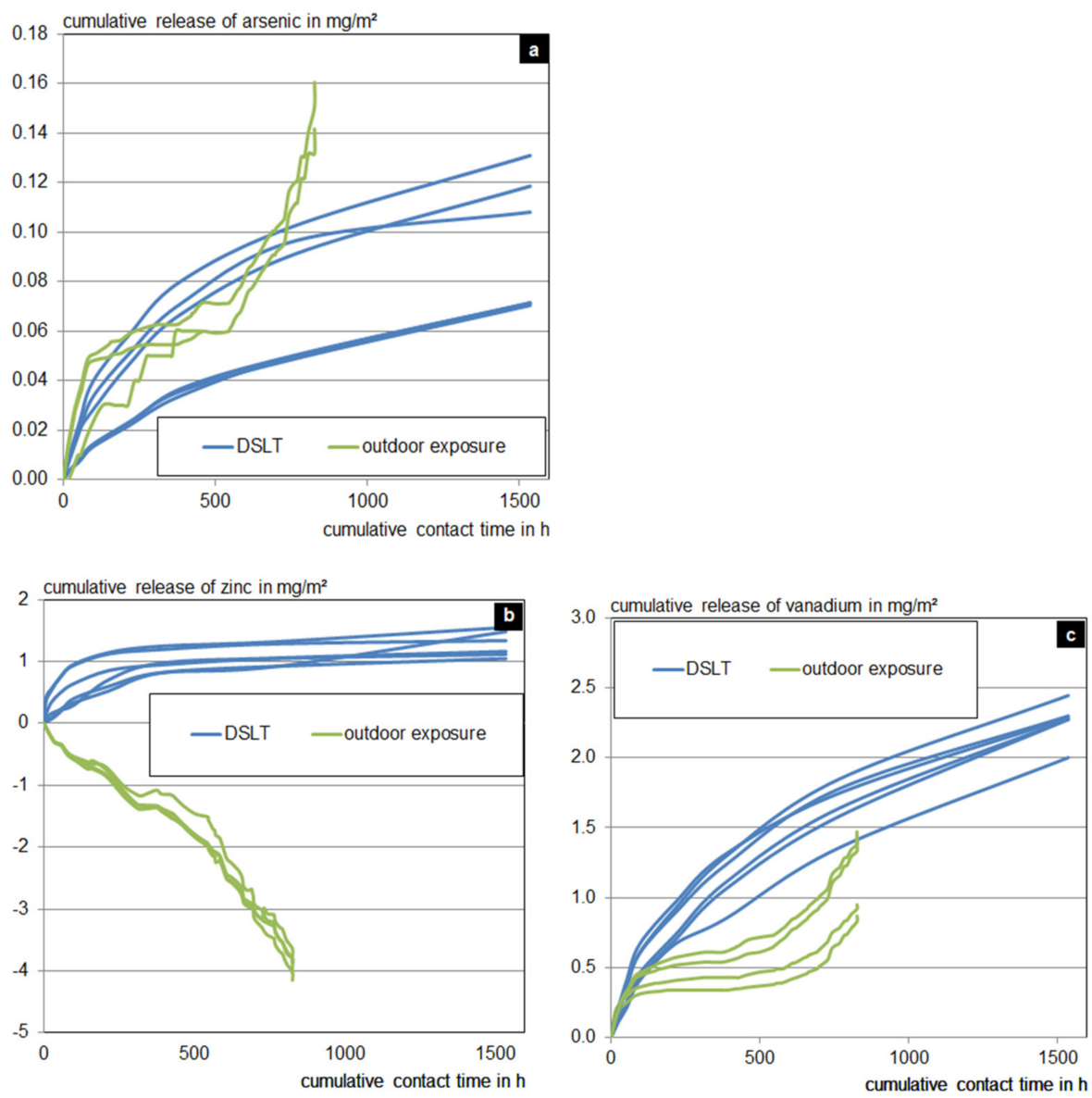

Figure 3. Cumulated emissions of (a) arsenic, (b) zinc and (c) vanadium in the dynamic surface leaching test and under outdoor exposure conditions (data of [11]).

\section{Assessment of Environmental Impacts}

Multiple scenarios are in use for assessing the environmental impact of substances. The source-path-target concept enables a complementary set of scenarios for an integrated and balanced assessment. It relies on
(a) individual process models;
(b) transport models; and
(c) software implementing the models.

\subsection{Source-Path-Target Concept}

The general principle of the source-path-target is as follows: the substances are released from the sources to neighbouring compartments and transported to the target, which 
is the decisive point of compliance. Along this pathway, multiple factors such as temperature, state of aggregation or chemical speciation can influence the fate and occurrence of the substances. The main release processes must be characterized. The different interfaces between the main processes should be modelled using the same resolution level as for the processes.

The terms "scenario" and "model" are part of the concept. Scenarios consider a number of processes occurring at different intensities at the source, during the path and in the target. Models are required and applied to describe these processes, e.g., estimation of the release of substances by statistical functions based on leaching test data. Each use case is described in a scenario with parameters that define the specific situation at the source, the transport parameters as well as target requirements.

Furthermore, these scenarios describe the interfaces between source, path and target and the transport processes within them. Based on state-of-the-art knowledge, size and initial substance contents of building components, a scenario represents the time- and space-dependent distribution and concentration of emitted substances.

The applied models and interfaces must have the same accuracy, data availability and granularity. Multidimensional mathematical models of such kind need to be converted into user-friendly documents or software tools.

\subsection{Scenarios}

Each scenario describes a sequence of processes that can lead to environmental harm. Regulators and scientists prepare scenarios as plausible simplifications of reality with the goal of representing the relevant environmental processes. Therefore, processes (or combinations thereof) need to be proofed by their relevance and simulation models identified that are adequate for the assessments. Adequate means that a more severe environmental impact correlates with a higher simulation result and the simulation model allocates the environmental impacts to the correct causes.

The scheme of Figure 4 encompasses different pathways in which substances may be transported from sources $(\mathrm{S})$ via different paths $(\mathrm{P})$ to the targets $(\mathrm{T})$, as indicated by light green arrows.

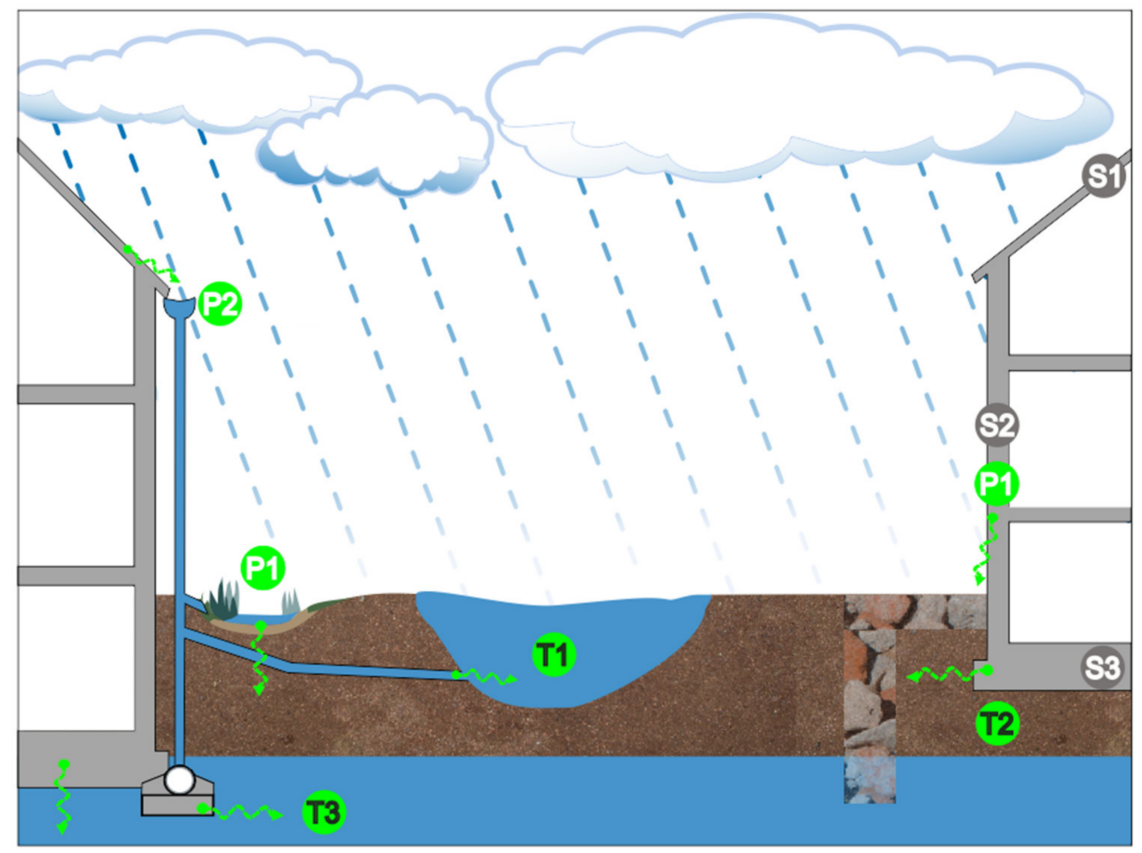

Figure 4. Visualization of parts of the scenario for the release of substances from construction products of the building envelopes to the environment. Possible sources are roofs (S1), facades (S2) and foundation (S3), paths are runoff (P1) and infiltration (P2), and targets can be water bodies (T1), soil (T2) and groundwater (T3). 
A scenario is a set of source, path and target parameters that are derived from use cases. The dimensions of the compartments and environmental observations need to be evaluated to enable mathematical calculations. Then, each scenario results in a single calculation of an impact. The impact assessment, however, consists of the consideration of all scenario results. Thus, the sum of substance transport from several pathways, one or $n$ buildings of different geometries and potential interaction effects need to be considered. The integration of scenarios for the assessment of the environmental impact of building components is illustrated in Figure 5.

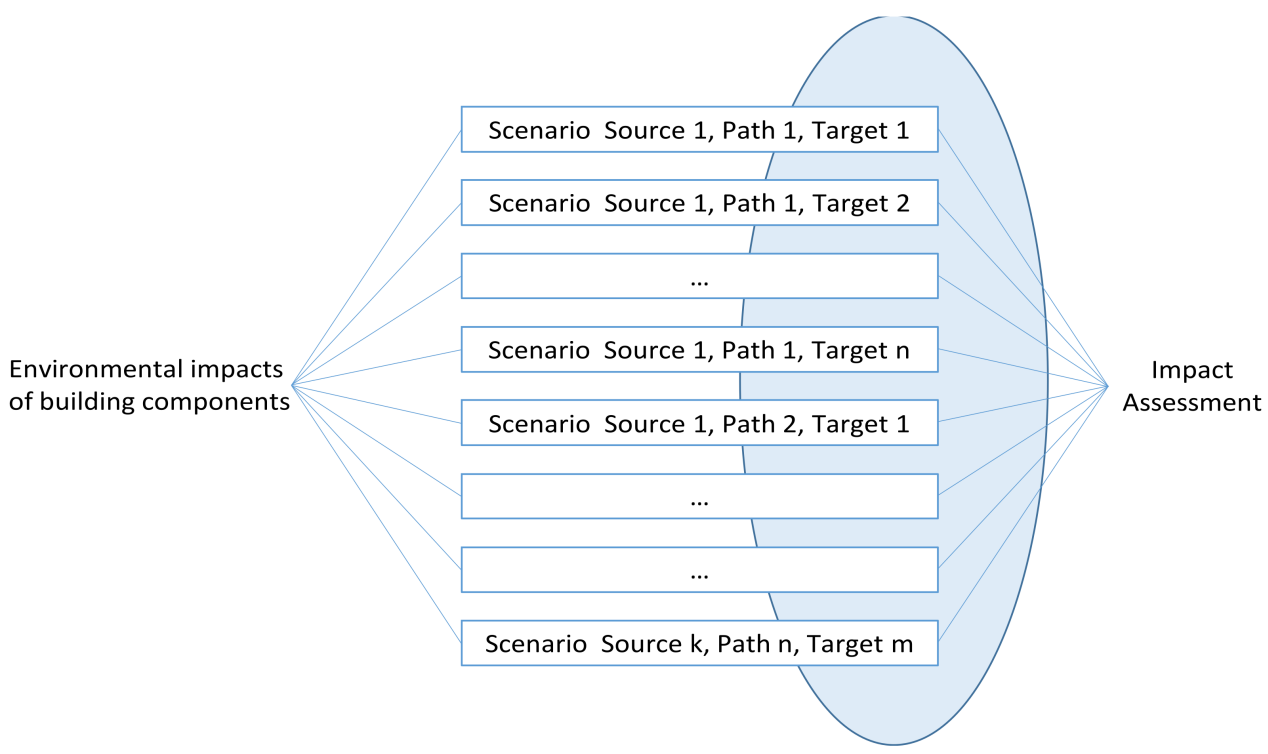

Figure 5. The Brunswikian lens model [44] of an impact assessment: The source-path-target concept determines which scenarios must be considered. Not all theoretically possible combinations of the $k$ sources, the $n$ paths and the $m$ targets are relevant for the impact assessment.

\subsubsection{Source Part of the Scenarios}

The building envelope is considered as the source for substance emission to the environment and is divided in different source compartments according to the building geometry and material class. The major compartments depicted in Figure 4 are:

(S1) Roofs, e.g., roof tiles, flexible membranes, concrete, roofing fabric, wood and metal sheets

(S2) Façades, renders, paints, wood, concrete, metal sheets and textiles. Windows, doors and balconies also belong to this category

(S3) Foundation (with permanent water contact), e.g., concrete, bitumen sheets and plastic sheets

These technical settings are translated to the following source line-up:

(a) Building envelope parameters, such as size, shape and location of the building components (either actual conditions or defined standard parameters like the "OECD house" which is a highly simplified model that is used for BPR risk assessments [45])

(b) Exposition characteristics, that use either actual weather conditions, such as duration, direction and intensity of precipitation or water contact or use standard conditions (e.g., FOCUS scenarios [46])

(c) Emissions described by functions, e.g., diffusion, transformation or encompassing emission functions

Leaching data and boundary condition parameters (e.g., weather data) are required to run simulations. Weather data are available across Europe (e.g., FOCUS, DWD, Meteoswiss). Weather stations that are not located near the study sites may not reflect the actual conditions and may be influenced by topography or surrounding buildings. If 
specific sites are to be evaluated (e.g., Spain, Germany or Switzerland), mean weather characteristics are available (see FOCUS [46]). Another source of uncertainty is the calculation of wind driven rain. Although a standard calculation exists (ISO 15927-3 [47]), its accuracy can hardly be proven. This is due to the empirical parameters used (roughness coefficient, wall coefficient, etc.). Moreover, wind-driven rain is not the same as the façade runoff water. Wind driven rain on a façade may also absorb into the material, splash or evaporate. The emission from the source is described as a mass flux of substances in units of mass per time from the building envelopes. The load of the compounds emitted depend on the surface area, the substances content in the material and the potential of the substances to be released via transport processes such as diffusion and capillary flux within the material. Sorption processes on the material matrix hinder release processes. Transformations, mainly chemical transformation of organic substances or phase transitions related to solubility and/or $\mathrm{pH}$ dependence of organic and inorganic compounds, can also take place and affect the released amount. In general, the release processes within the material are triggered by moisture. Significant leaching can only be observed for moistened façade material. Hence, the water contact time is a dominant influencing parameter for leaching. At the surface of the building envelope, the intensity and frequency of water contact by rain, groundwater or dew are driving factors for substance release. The total source emission encompasses all release processes at the source until the substance enters the transport pathway ("path"). The processes at the interface of "source" and "path" are capillary flow, diffusion, sorption and degradation. Phase transitions at the surface, i.e., evaporation to air is usually neglected in the models.

The translation of processes at the building envelope into a mathematical description is illustrated for façades in Figure 6. Water on a façade favours diffusion or dissolution of substances into the contacting droplets or water film. Above a certain threshold value of wind-driven rain (wind direction, amount of water) on façades, runoff flows either as a film or in channels along the façade into the adjacent environmental compartment [48]. The substance concentration in the runoff water at the top of the component equals zero. The outflow concentration at the bottom of the component is maximal. If the component is porous, part of the wind driven rain is absorbed by the component due to capillary suction and evaporates under dry conditions. Water evaporates from the material but on its way back to the surface, it transports part of the dissolved contaminants to the surface via convection (wet-dry stress, see [11]). Even if the material is not porous, substances may diffuse to the surface because of a concentration, temperature or moisture gradient between the component and its surface.

Wangler et al. show that the leaching process of biocides from organic coatings is controlled by diffusion $[49,50]$. This relies on the fact that from the boundary value problem for the diffusion process within a plate, a root function describes the outflow. Schoknecht et al. [27] described the outflow concentrations on a double log scale by a linear function with a slope of 0.5 for a certain period of field experiments, which is consistent with the diffusion-controlled release presented in the DSLT-document prEN 16337-2 [33].

While rate constants and diffusion coefficients describe leaching processes on a small scale, the product and building scale are dominated by the heterogeneity of initial substance amounts and weather conditions (e.g., transfer from the products matrix into the water phase within the product or desorption and decay).

Basic information for understanding leaching processes can be the identification of phases controlling the release of substances. For example, the transport of reactive substances through (reactive) porous media leads to the release of material constituents and ingress of external reacting substances, showing that porosity is an important factor [51-54]. Thermodynamic and transport modelling can be combined to simulate experimental results and the chemical behaviour of materials in different application scenarios. This way it is possible to estimate emissions from mineral building materials, provided that all relevant substances are included in the applied database. Organic constituents of concern are not 
implemented in the databases and the possible reactions are probably too complex to model in the current state.

Vega-Garcia et al. [55] successfully applied a dynamic leaching model using the geochemical software PhreeQC $[52,53]$ to describe the leaching of selected metals and sulfate for plasters and mortars in the field. In this example, the results of leaching tests, mineralogical composition and runoff data derived from a model are needed as input parameters [56].

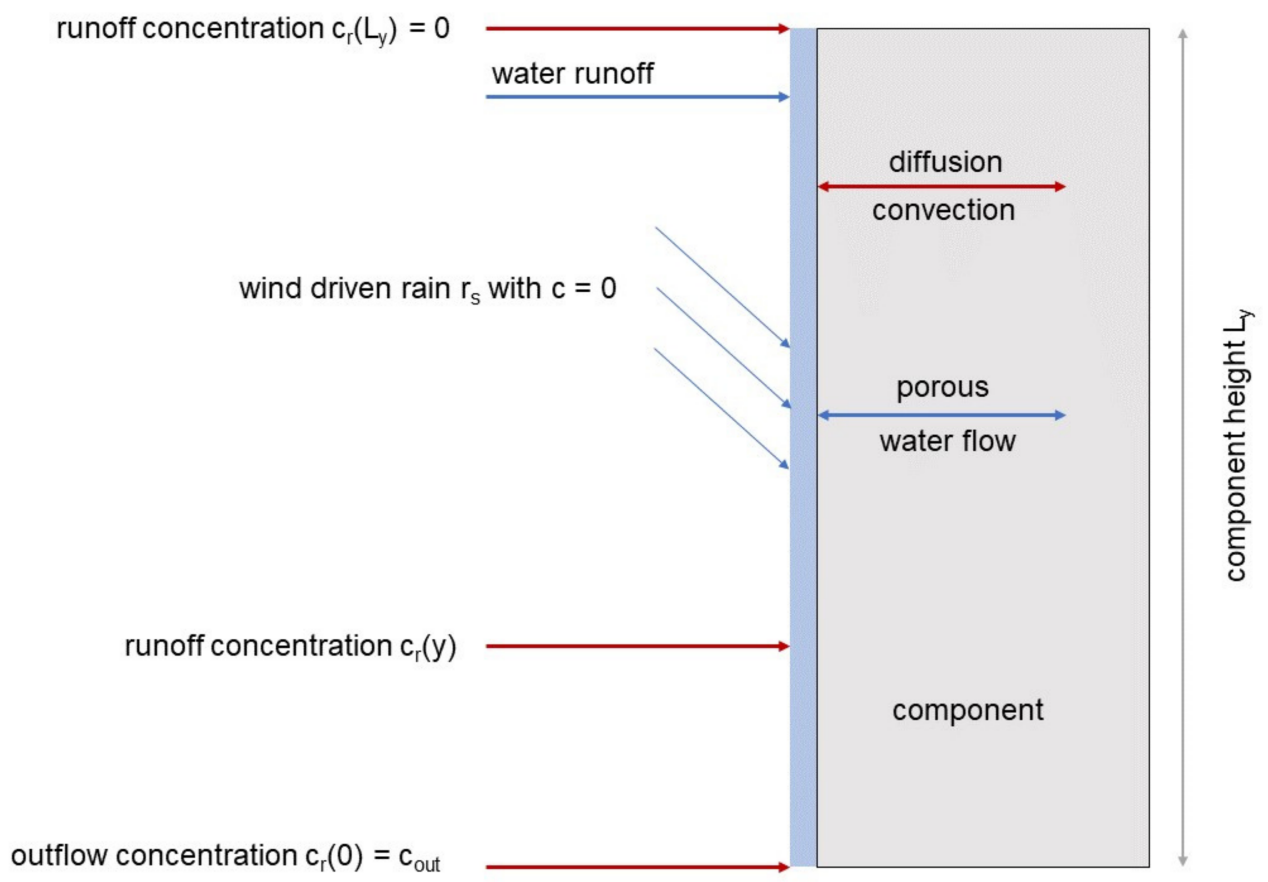

Figure 6. Leaching processes in a building material at a façade.

The emissions of inorganic substances from concrete on a smaller scale can be described by functions derived from outdoor data by multiple regression. The influence of interactions of the ageing matrix and weather conditions on the substance leaching varies for different groups of substances but is determined by and can be described by several parameters: Exposure time, contact time, air temperature and humidity and runoff volume. Additionally, for substance uptake from rain, the rain $\mathrm{pH}$ and respective background concentrations are decisive. Material parameters are not included in the calculation of emissions. The main leaching mechanisms (solution and diffusion) remain important but are significantly superimposed by outdoor influences with different impacts on the particular substances. A transfer of the derived functions to substances with similar leaching behaviour was successfully conducted by varying a constant in the regression term. Yet, the functions are to be verified by further tests, and a method to determine the constant on a laboratory scale should be developed [43].

Mathematical models were applied to describe leaching processes under outdoor conditions, i.e., regression approaches combined leaching data from field experiments and weather conditions $[27,43]$, and a slope-based analysis of leaching curves was intended to identify periods that are controlled by different processes [57].

Emission functions based on statistical regression of available data [58] relate inputs of a substance (i.e., the initial amount within the construction product) and the main processes (weather conditions, material properties) to the output (leaching). These functions are derived by extrapolation of field or laboratory test data and can be used to predict emissions of substances. For example, the model used in COMLEAM (Table 1) takes into account substance characteristics, weather data, building material properties and exposition characteristics to predict emissions. Such models may serve as the best current concepts for 
impact assessment. Different emission functions can be compared so that the most realistic and plausible simulation can be selected for modelling [58].

\subsubsection{Paths within the Scenarios}

The paths describe the transport of the substances from the source to the target compartments. The description encompasses the following framework:

(a) Boundary conditions and transport parameters, e.g., transport distance, dilution, or soil parameters

(b) Transport modelling of stormwater runoff, infiltration, and discharge to surface waters (e.g., using linear reservoir concepts, one- or multi-dimensional soil transport models or empirical/statistical equations)

The emission of substances from building envelopes to the environment occurs via infiltration into the soil (P1) or direct discharge (P2). There are several models that describe transport processes in the main environmental compartments soil, surface water and groundwater.

The 1D FOCUS Models (e.g., PELMO [59], Pearl [60]) and pedotransfer functions [61] address transport in unsaturated soils triggered by precipitation, substance and soil properties. The organic matter, $\mathrm{pH}$ value, adsorption and degradation constants of the considered substances and thickness of the soil layers have a significant effect on the transport distance.

Typical groundwater models are, for example, FEFLOW [62] and ModFlow [63] (see also [64]). Geochemical models like PhreeQC [52] can be applied for subsurface flow. Multidimensional models are difficult to validate with environmental measurements.

The model COMLEAM is addressing stormwater runoff and can be coupled with sewer models like SWMM for complex hydrological pathways. Water flow and concentration patterns are significantly influenced by the runoff coefficients of surfaces.

\subsubsection{Target Part of the Scenario}

As indicated in Figure 4, targets of emissions from buildings are surface water (T1), soil (T2) and groundwater (T3). The impact variables are

(a) Location of the points of compliance

(b) Time of evaluation, e.g., average values, maxima, minima

(c) Alignment with limit values, e.g., for acute or chronic effects

Concentrations with no or only certain effects on organisms (e.g., NOEC-no effect concentration; EC - effect concentrations) result in the definition of limit values. Authorities define points of compliance where limit values are to be met, i.e., determine the endpoint as well as the assessment of the results of model calculations that describe the fate of substances.

In certain cases, this approach cannot be applied, e.g., when leached substances or their effects on organisms are unknown, or when unknown mixtures of substances and/or transformation products are to be evaluated. In those cases, ecotoxicity tests for construction products $[65,66]$ are proposed as a tool to identify unwanted effects on selected target organisms. This concept is used, e.g., as a criterion for the German environmental label "Blauer Engel" for concrete with recycled mineral aggregates for outdoor paving [67]. This effect-based approach is not directly connected to models that describe the fate of substances.

\subsection{Software Models}

The release of substances from buildings or comparable applications of construction products can be assessed by commercially or public domain software based on mathematical models (Table 1). Mostly, a combination of different models is available for describing the source-path-target approach.

Software with applications for the assessment of impacts of building components 
(a) combine processes, such as adsorption and desorption, decay or other transformations, dissolution/precipitation,

(b) include diffusive, convective transport or simplifying compartment models within or on different materials or in unsaturated or saturated soil, in surface water or channels, and

(c) provide graphical representations for the evaluation and prepare the comparison of model results with threshold values.

Table 1. Examples of software used in science and regulations.

\begin{tabular}{|c|c|c|c|}
\hline Software & $\begin{array}{c}\text { Source: } \\
\text { Modelling of Emission }\end{array}$ & $\begin{array}{l}\text { Path: } \\
\text { Transport to the Point of } \\
\text { Compliance }\end{array}$ & $\begin{array}{l}\text { Target: } \\
\text { Alignment with Limit Values } \\
\text { at the Point of Compliance }\end{array}$ \\
\hline $\begin{array}{l}\text { COMLEAM [68]-products in } \\
\text { contact with rainfall }\end{array}$ & $\begin{array}{c}\text { Emission functions } \\
\text { (logarithmic, diffusion etc.) } \\
\text { including wind-driven rain }\end{array}$ & $\begin{array}{l}\text { Surface runoff reflected by } \\
\text { linear reservoirs }\end{array}$ & $\begin{array}{c}\text { Comparison to thresholds, } \\
\text { e.g., at the building, in surface } \\
\text { water }\end{array}$ \\
\hline $\begin{array}{l}\text { PhreeQC [52]—subsurface } \\
\text { water contact }\end{array}$ & $\begin{array}{l}\text { Reactions mainly addressing } \\
\text { inorganic substances }\end{array}$ & $\begin{array}{l}\text { Transport through the aquifer } \\
\text { including chemical reactions }\end{array}$ & $\begin{array}{l}\text { Comparison to groundwater } \\
\text { limit values }\end{array}$ \\
\hline $\begin{array}{l}\text { LeachXS and Orchestra } \\
\text { [51]— construction materials } \\
\text { in contact with soil and water }\end{array}$ & $\begin{array}{l}\text { Speciation and diffusion of } \\
\text { substances }\end{array}$ & $\begin{array}{l}\text { Unsaturated soil including, } \\
\text { e.g., pH-dependent sorption }\end{array}$ & $\begin{array}{c}\text { Comparison to thresholds in } \\
\text { soil and water }\end{array}$ \\
\hline $\begin{array}{l}\text { FOCUS Pelmo [59], } \\
\text { Pearl [60]—transport in } \\
\text { unsaturated soil }\end{array}$ & $\begin{array}{l}\text { Input at time series for } \\
\text { different substances }\end{array}$ & $\begin{array}{l}\text { Unsaturated soil including } \\
\text { sorption and degradation }\end{array}$ & $\begin{array}{l}\text { Comparison to thresholds in } \\
\text { the saturated subsurface }\end{array}$ \\
\hline $\begin{array}{l}\text { FEFLOW [62], ModFlow } \\
\text { [63]-transport in seepage } \\
\text { water and groundwater }\end{array}$ & $\begin{array}{l}\text { Variable source term (e.g., } \\
\text { surface-related release) }\end{array}$ & $\begin{array}{l}\text { Groundwater including } \\
\text { reactive multi-species } \\
\text { transport }\end{array}$ & $\begin{array}{l}\text { Comparison to thresholds in } \\
\text { seepage water and } \\
\text { groundwater }\end{array}$ \\
\hline
\end{tabular}

It should be noted that software used for heat and moisture transport modelling such as DELPHIN $[69,70]$ might also describe the transport of substances such as ions, but so far, these models do not address environmental impact.

\section{Application in Policy Fields and Regulations}

Several European regulations [22-25] consider construction products as sources of concerning substances in the environment. Technical choices for construction products should consider environmental impact. This concerns product development, the implementation of CPR essential requirement 3 in product standards, CE marketing and product authorization, the re-use of construction materials and the use and application of construction products.

Standardized test procedures determine the emissions from construction products under defined laboratory conditions (see Section 2). Models and software applications are available to describe the release and environmental exposure of substances (see Section 3). Emission scenarios have been defined for different applications, e.g., for biocides used as material preservatives [45]. Finally, calculated output data are expressed in the required units for the existing requirements, i.e., results can be expressed either as concentrations in water or soil or as released amounts in different time frames related to surface area, constructions or regions. This allows the application of the source-path-target concept for different purposes [45,71]. For example, a tiered approach allows for assessments and refinements depending on the expected environmental risk.

Risk assessments depend on parameters that must be defined for scenarios as well as model calculations. Currently, the member states apply individual rules for environmental risk assessments. For example, although both the Netherlands and Germany apply the source-path-target concept, the different assumptions for the parameters in scenarios and model calculations result in different conventions and therefore lead to a different outcome of the risk assessments (Figure 7). From a European perspective, this outlines the 
necessity to harmonize procedures and parameters for the environmental risk assessment of construction products or-at least-to design these procedures transparently.

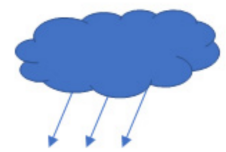

Source

Path

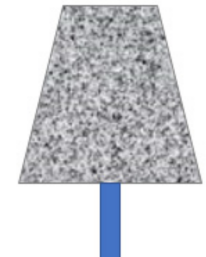

Target

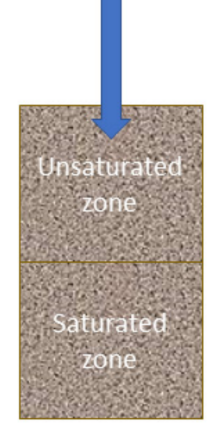

Netherlands Germany

Concentration of substances

Time

Infiltration

$242-583 \mathrm{~mm} / \mathrm{y}$

Point of

compliance
$300 \mathrm{~mm} / \mathrm{y}$

Decreasing Constant

100 years $\quad 200$ years

Average first $1 \mathrm{~m}$ depth

$1 \mathrm{~m}$ of under

saturatedzone application

Figure 7. Different definitions of parameters in scenarios for risk assessments in the Netherlands and Germany (adapted and simplified from [72]).

In Switzerland, the aquatic risk of dangerous substances entering surface waters from renders and flexible membranes for roof waterproofing is evaluated with a holistic concept [73]. Based on substance properties (e.g., half-life in soils/sediment (DT50), ecotoxicity), the two most relevant substances are selected to study their leaching behaviour (EN 16105, DSLT), followed by a COMLEAM simulation of an urban scenario with the direct discharge of stormwater in reference to acute and chronic limit values. For the extrapolation to a service life of five years, the lab data are extrapolated by use of an emission function, which is typically a logarithmic equation. Overall, products with nearly negligible aquatic risk are assigned to the best class, which indicates no concern to aquatic organisms. Products that pose a risk to aquatic systems are classified in the third (and worst) class, requiring treatment measures before stormwater infiltration or direct discharge to surface waters.

The model COMLEAM has been used to derive insights into the representativeness of existing BPR Emission Scenario Documents (ESD) for product type 7 [74]. The result demonstrated that ESDs overestimate the emission amount on the one hand and underestimate the aquatic risk on the other. A tiered risk evaluation or a refinement using the dynamic COMLEAM model would reflect the real-world emissions more realistically. This result significantly improves the source-path-target concept to protect surface waters and provides producers with clear guidance for potential mitigation measures.

In Germany, a regulation on the recycling of building materials will be implemented in 2023 to predict concentrations of hazardous substances in seepage water, which is in line with the source-path-target concept [20]. In this case, fixed-scenario boundary conditions are defined. The choice of source term and pathway based upon existing conventions for average weather conditions and integrated assumptions of model parameters allows to derive unambiguous limit values for each scenario. These limit values are disclosed in the regulation and are publicly accessible for use in specific application cases without the necessity to perform specific model calculations with software applications. 
For new building materials, which require technical approval, the German authority DIBt (Deutsches Institut für Bautechnik, Berlin, Germany) evaluates the environmental exposure based on specific scenarios adapted to the intended use of the product [75]. Figure 8 exemplarily shows the scenario for concrete and concrete constituents. The concentrations are evaluated in the soil layer behind the building, where the highest concentrations are expected. These concentrations are averaged over a distance of $2 \mathrm{~m}$ from the concrete surface and a period of six months. So far, this concept considers diffusion, dispersion and advection in the transport term. Subsequent sorption processes and degradation in the in-situ compartments are neglected.

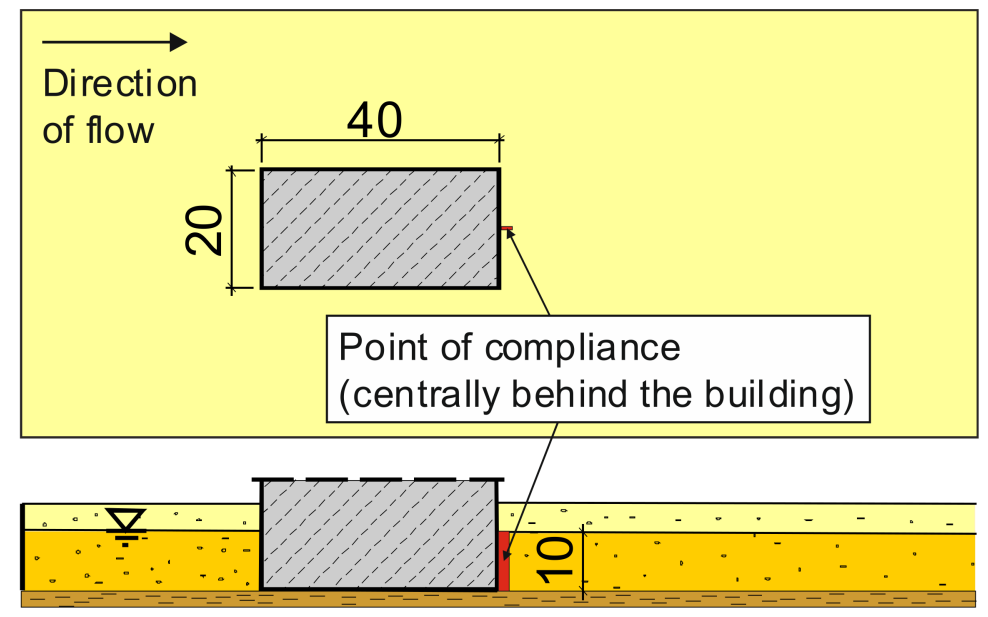

Figure 8. Top view and cross-section of the model scenario for concrete and concrete constituents (dimensions in $\mathrm{m}$ ) adapted from [75], part II.

\section{Conclusions and Outlook}

The conceptual framework for an environmental impact assessment is summarized in Figure 9 and consists of a set of tools and methods. The concept integrates the most relevant aspects of measurements, scientific models and regulatory requirements. Thus, it is a valuable basis for the development of sustainable construction products. Numerous tools and methods required to implement this concept have already been developed. First experiences in the application of this concept have already been made.

Further efforts are required to put this concept for construction products into practice at a European level. The authors of this manuscript recommend developing consistent concepts throughout Europe to interlink knowledge, optimize effort and costs on the one hand and to obtain generally accepted procedures and avoid trade barriers on the other hand. These concepts need to be adaptable to different specifications that consider, for example, local characteristics. Additionally, the concept shall enable producers to identify key factors to reduce the release of dangerous substances.

Although standardized test procedures to determine the release of substances from construction materials are available, these procedures need to be adapted for different types of construction products. Application of results from laboratory tests needs to be specified for risk assessments. This is supported by models that consider use conditions and transport processes and usually refer to emission scenarios.

According to the source-path-target concept, mathematical models are crucial to represent the knowledge about the underlying emission and transport processes and inputoutput relations, to use the available data from laboratory and field tests and to combine the parameters assumed in the emission scenarios.

Although there are a lot of models available, they have been developed for separate issues and policy fields. Closing the gaps in the field of construction product environmental risk assessment need substantial efforts to cover the broad scope of construction products area as follows: 
- determine processes that have not been described so far and integrate these processes in models

- compare models to figure out sensitive parameters and lacking processes

- combine available and newly developed models in a toolbox

- define harmonized scenarios representing the most important areas of application in Europe

A generally accepted assessment concept for construction products shall enable the use of estimated environmental impact data under different scenarios and regulatory requirements by users with different scientific or regulatory skills.

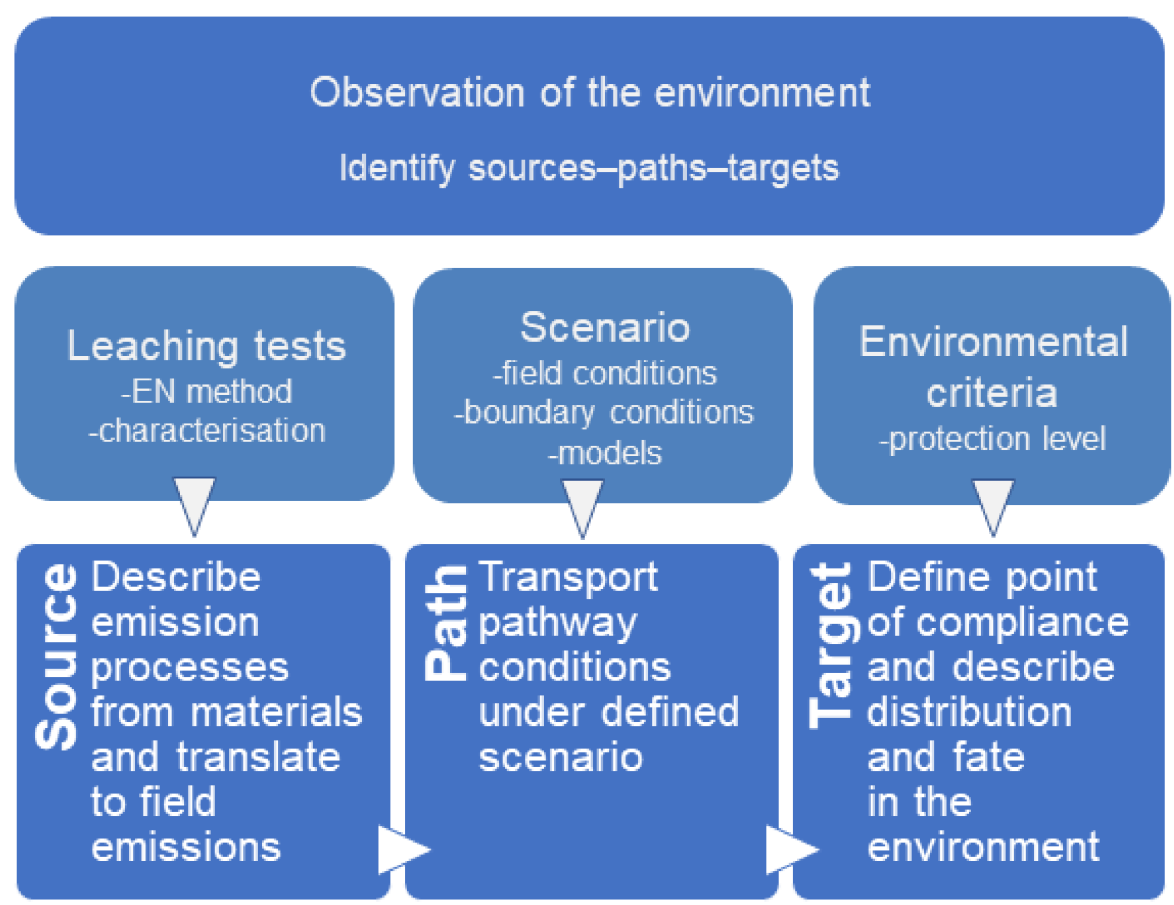

Figure 9. Conceptual framework for environmental impact assessment of (re)-use of construction materials.

In general, the application of this approach is based on several assumptions. Laboratory tests cannot reflect real-use conditions. Translating laboratory results into models is a possibility to include additional aspects such as use and weather conditions into impact assessments. However, this cannot replace the knowledge on the influence of additional parameters, e.g., varying temperature, water quality or global radiation. Nevertheless, the actual environmental conditions to which building materials are subjected to are more complex than represented by laboratory tests and the adaption of data within models. In this sense, the outcome of models does not reflect real conditions, i.e., the application of models is based on assumptions that need to be harmonized to improve the transparency and comparability of results. These assumptions include acknowledged emission scenarios and a selection of models to describe the release and transport of substances. The definition of a limited number of harmonized emission scenarios is required to improve the implementation and comparability of model calculations. Predicting representative simulations of all possible scenarios is also challenging. Gaps between laboratory tests, mathematical models and real emission scenarios cannot be completely avoided. Therefore, the outcome of model calculations should be compared to measurements under real conditions to validate the environmental risk assessments. Certainly, the presented approach is a suitable way to identify the unwanted environmental impact of building materials. 
Author Contributions: Conceptualization and Writing, Original Draft Preparation, U.S., O.T., N.B., M.B., M.R., A.V. and L.W. All authors have read and agreed to the published version of the manuscript.

Funding: This research received no external funding.

Data Availability Statement: No original data are presented in this paper.

Acknowledgments: The authors thank André van Zomeren (TNO), Hans van der Sloot (Hans van der Sloot Consultancy) and Michael Klein (Fraunhofer IME) for their contribution to the fundamental concept of this paper and Michael Patrick, UMTEC, for proofreading the manuscript.

Conflicts of Interest: The authors declare no conflict of interest.

\section{References}

1. Lebow, S.; Lebow, P.; Foster, D. Estimating preservative release from treated wood exposed to precipitation. Wood Fiber Sci. 2008, 40, 562-571.

2. Bucheli, T.D.; Muller, S.R.; Voegelin, A.; Schwarzenbach, R.P. Bituminous roof sealing membranes as major sources of the herbicide (R,S)-mecoprop in roof runoff waters: Potential contamination of groundwater and surface waters. Environ. Sci. Technol. 1998, 32, 3465-3471. [CrossRef]

3. Vollpracht, A.; Brameshuber, W. Environmental compatibility of bitumen waterproofing. Mater. Struct. 2013, 46, 1257-1264 [CrossRef]

4. $\quad$ Burkhardt, M.; Zuleeg, S.; Vonbank, R.; Bester, K.; Carmeliet, J.; Boller, M.; Wangler, T. Leaching of biocides from facades under natural weather conditions. Environ. Sci. Technol. 2012, 46, 5497-5503. [CrossRef]

5. Bollmann, U.E.; Minelgaite, G.; Schlüsener, M.; Ternes, T.; Vollertsen, J.; Bester, K. Leaching of terbutryn and its photodegradation products from artificial walls under natural weather conditions. Environ. Sci. Technol. 2016, 50, 4289-4295. [CrossRef] [PubMed]

6. Bollmann, U.E.; Minelgaite, G.; Schlüsener, M.; Ternes, T.A.; Vollertsen, J.; Bester, K. Photodegradation of octylisothiazolinone and semi-field emissions from facade coatings. Sci. Rep. 2017, 7, screp41501. [CrossRef]

7. Lupsea, M.; Tiruta-Barna, L.; Schiopu, N. Leaching of hazardous substances from a composite construction product-An experimental and modelling approach for fibre-cement sheets. J. Hazard. Mater. 2014, 264, 236-245. [CrossRef]

8. Schoknecht, U.; Mathies, H.; Wegner, R. Biocide leaching during field experiments on treated articles. Environ. Sci. Eur. 2016, 28, 1-10. [CrossRef]

9. Vermeirssen, E.L.M.; Dietschweiler, C.; Werner, I.; Burkhardt, M. Corrosion protection products as a source of bisphenol A and toxicity to the aquatic environment. Water Res. 2017, 123, 586-593. [CrossRef]

10. Hartwich, P.; Vollpracht, A. Influence of leachate composition on the leaching behaviour of concrete. Cem. Concr. Res. 2017, 100, 423-434. [CrossRef]

11. Weiler, L.; Vollpracht, A. Leaching of carbon reinforced concrete-Part 1: Experimental investigations. Materials 2020, 13, 4405. [CrossRef]

12. Märkl, V.; Pflugmacher, S.; Stephan, D.A. Leaching of PCE-based superplasticiser from microfine cement: A chemical and ecotoxicological point of view. Water Air Soil Pollut. 2017, 228, 217. [CrossRef]

13. Heisterkamp, I.; Gartiser, S.; Kalbe, U.; Bandow, N.; Gloßmann, A. Assessment of leachates from reactive fire-retardant coatings by chemical analysis and ecotoxicity testing. Chemosphere 2019, 226, 85-93. [CrossRef]

14. Burkhardt, M.; Rohr, M.; Heisterkamp, I.; Gartiser, S. Niederschlagswasser von Kunststoffdachbahnen-Auslaugung von Stoffen und deren Ökotoxizität für aquatische Organismen. Korresp. Wasserwirtsch. 2020, 13, 418-424. [CrossRef]

15. Jungnickel, C.S.; Stock, F.; Brandsch, T.; Ranke, J. Risk assessment of biocides in roof paint. Environ. Sci. Pollut. Res. 2008, 15, 258-265. [CrossRef]

16. Burkhardt, M.; Zuleeg, S.; Schmid, P.; Hean, S.; Lamani, X.; Bester, K.; Boller, M. Leaching of additives from construction materials to urban storm water runoff. Water Sci. Technol. 2011, 63, 1974-1982. [CrossRef]

17. Bollmann, U.E.; Vollertsen, J.; Carmeliet, J.; Bester, K. Dynamics of biocide emissions from buildings in a suburban stormwater catchment-Concentrations, mass loads and emission processes. Water Res. 2014, 56, 66-76. [CrossRef]

18. Paijens, C.; Bressy, A.; Frère, B.; Moilleron, R. Biocide emissions from building materials during wet weather: Identification of substances, mechanism of release and transfer to the aquatic environment. Environ. Sci. Pollut. Res. 2020, 27, 3768-3791. [CrossRef] [PubMed]

19. Müller, A.; Österlund, H.; Nordqvist, K.; Marsalek, J.; Viklander, M. Building surface materials as sources of micropollutants in building runoff: A pilot study. Sci. Total Environ. 2019, 680, 190-197. [CrossRef] [PubMed]

20. Verordnung zur Einführung einer Ersatzbaustoffverordnung, zur Neufassung der Bundes-Bodenschutz-und Altlastenverordnung und zur Änderung der Deponieverordnung und der Gewerbeabfallverordnung. Bundesgesetzblatt Jahrgang 2021 Teil I Nr. 43 zu Bonn am 16. 2021. Available online: https:/ / www.bgbl.de (accessed on 8 November 2021).

21. Waterstraat, S.v.I.e. Regeling Bodemkwaliteit BWBR0023085, Staatscourant 2007. Available online: https://wetten.overheid.nl/ BWBR0023085/2021-01-21 (accessed on 8 November 2021). 
22. European Parliament and Concil. Regulation (EU) No 305/2011 Laying Down Harmonised Conditions for the Marketing of Construction Products and Repealing Council Directive 89/106/EEC. Available online: https:/ / eur-lex.europa.eu/legal-content/ $\mathrm{EN} / \mathrm{TXT} /$ ?uri=celex\%3A32011R0305 (accessed on 8 November 2021).

23. European Parliament and Concil. Regulation (EU) No 528/2012 Concerning the Making Available on the Market and Use of Biocidal Products. Available online: https:/ / echa.europa.eu/regulations/biocidal-products-regulation/legislation (accessed on 8 November 2021).

24. European Parliament and Concil. Regulation (EU) No 1907/2006 concerning the Registration, Evaluation, Authorisation and Restriction of Chemicals (REACH). Available online: https://echa.europa.eu/regulations/reach/legislation (accessed on 8 November 2021).

25. European Parliament and Concil. Directive 2000/60/EC Establishing a Framework for the Community Action in the Field of Water Policy. Available online: https:/ / eur-lex.europa.eu/legal-content/EN/TXT/?uri=celex:32000L0060 (accessed on 8 November 2021).

26. Van der Sloot, H.A.; Heasman, L.; Quevauviller, P. Harmonization of Leaching/Extraction Tests. Studies in Environmental Science 70; Elsevier: Amsterdam, The Netherlands, 1997.

27. Schoknecht, U.; Mathies, H.; Wegner, R.; Uhlig, S.; Baldauf, H.; Colson, B. Emissions of Material Preservatives into the Environment-Realistic Estimation of Environmental Risks through the Improved Characterization of the Leaching of Biocides from Treated Materials Used Outdoors, UBA-Texte 22/2016. Available online: https:/ / www.umweltbundesamt.de/publikationen (accessed on 8 November 2021).

28. Hensen, B.; Lange, J.; Jackisch, N.; Zieger, F.; Olsson, O.; Kümmerer, K. Entry of biocides and their transformation products into groundwater via urban stormwater infiltration systems. Water Res. 2018, 144, 413-423. [CrossRef] [PubMed]

29. Vega-Garcia, P.; Schwerd, R.; Scherer, C.; Schwitalla, C.; Johann, S.; Rommel, S.H.; Helmreich, B. Influence of façade orientation on the leaching of biocides from building façades covered with mortars and plasters. Sci. Total Environ. 2020, 734, 139465. [CrossRef] [PubMed]

30. Vega-Garcia, P.; Schwerd, R.; Johann, S.; Helmreich, B. Groundwater risk assessment of leached inorganic substances from façades coated with plasters and mortars. Chemosphere 2021, 287, 132176. [CrossRef]

31. Umweltbundesamt. Schadstoffe aus Gebäuden in der urbanen Umwelt. Available online: https://www.umweltbundesamt.de/ themen/wirtschaft-konsum/produkte/bauprodukte/studien-zur-messung-vermeidung-bewertung-von/schadstoffe-ausgebaeuden-in-der-urbanen-umwelt (accessed on 8 November 2021).

32. prEN 16637-1:2021. Construction Products-Assessment of Release of Dangerous Substances—Part 1: Guidance for the Determination of Leaching Tests and Additional Testing Steps. Available online: https://www.beuth.de/de/norm-entwurf/din-en-1663 7-1/333142709 (accessed on 8 November 2021).

33. prEN 16637-2:2021. Construction Products-Assessment of Release of Dangerous Substances—Part 2: Horizontal Dynamic Surface Leaching Test. Available online: https:/ /www.beuth.de/de/norm-entwurf/din-en-16637-2/333142841 (accessed on 8 November 2021).

34. prEN 16637-3:2021. Construction Products-Assessment of Release of Dangerous Substances-Part 3: Horizontal Up-Flow Percolation Test. Available online: https://www.beuth.de/de/norm-entwurf/din-en-16637-3/333714058 (accessed on 8 November 2021).

35. Hjelmar, O.; Hykš, J.; Wahlström, M.; Laine-Ylijoki, J.; van Zomeren, A.; Comans, R.; Kalbe, U.; Schoknecht, U.; Krüger, O.; Grathwohl, P.; et al. Robustness Validation of TS-2 and TS-3 Developed by CEN/TC351/WG1 to Assess Release from Products to Soil, Surface Water and Ground Water, Report. 2013. Available online: https://www.nen.nl/media/Overig/WG_1_Robustness_ Validation_Report_-_TS-2_and_TS-3_-_Leaching_methods.pdf (accessed on 8 November 2021).

36. CEN/TS 15119-1:2018. Durability of Wood and Wood-Based Products-Determination of Emissions from Preservative Treated Wood to the Environment-Part 1: Wood Held in the Storage Yard after Treatment and Wooden Commodities Exposed in Use Class 3 (Not Covered, Not in Contact with the Ground)—Laboratory Method. Available online: https://www.beuth.de/de/ technische-regel/din-cen-ts-15119-1/273687697 (accessed on 8 November 2021).

37. EN 16105:2021. Paints and Varnishes-Laboratory Method for Determination of Release of Substances from Coatings in Intermittent Contact with Water. Available online: https:/ /www.beuth.de/de/norm-entwurf/din-en-16105/334706949 (accessed on 8 November 2021).

38. Schoknecht, U.; Sommerfeld, T.; Borho, N.; Bagda, E. Interlaboratory comparison for a laboratory leaching test procedure with facade coatings. Prog. Org. Coat. 2013, 76, 351-359. [CrossRef]

39. CEN/TS 16663:2016. Durability of Wood and Wood-Based Products-Determination of Emissions from Preservative Treated Wood to the Environment-Wooden Commodities Exposed in Use Class 3 (Not Covered, Not in Contact with the Ground)Semi-Field Method. Available online: https://www.beuth.de/de/technische-regel/din-cen-ts-16663/248829340 (accessed on 8 November 2021)

40. EN 14429:2015. Characterization of Waste-Leaching Behaviour Test-Influence of pH on Leaching with Initial Acid/Base Addition. Available online: https://www.beuth.de/de/norm/din-en-14429/216836654 (accessed on 8 November 2021).

41. EN 14997:2015. Characterization of Waste-Leaching Behaviour Test-Influence of $\mathrm{pH}$ on Leaching with Continuous $\mathrm{pH}$ Control. Available online: https:/ / www.beuth.de/de/norm/din-en-14997/219309172 (accessed on 8 November 2021).

42. Nebel, H.; Vollpracht, A.; Brameshuber, W. Auslaugverhalten von Putzen und Mörteln. Mauerwerk 2012, 16, 2-9. [CrossRef] 
43. Weiler, L.; Vollpracht, A.; Matschei, T. Leaching of carbon reinforced concrete-Part 2: Discussion of evaluation concepts and modelling. Materials 2020, 13, 4937. [CrossRef]

44. Scholz, R.W.; Tietje, O. Embedded Case Study Methods: Integrating Quantitative and Qualitative Knowledge; SAGE Publications: Thousand Oaks, CA, USA, 2002.

45. ECHA. Available online: https://echa.europa.eu/web/guest/information-on-chemicals/biocidal-active-substances (accessed on 8 November 2021).

46. FOCUS Scenarios. Available online: https://esdac.jrc.ec.europa.eu/public_path/projects_data/focus/gw/NewDocs/ GenericGuidance2_2.pdf (accessed on 8 November 2021).

47. EN ISO 15927-3:2009. Hygrothermal Performance of Buildings-Calculation and Presentation of Climatic Data-Part 3: Calculation of a Driving Rain Index for Vertical Surfaces from Hourly Wind and Rain Data (ISO 15927-3:2009). Available online: https:/ / www.beuth.de/de/norm/din-en-iso-15927-3/111122879 (accessed on 8 November 2021).

48. Blocken, B.; Carmeliet, J. A review on wind-driven rain research in building science. J. Wind. Eng. Ind. Aerodyn. 2004, 92, 1079-1130. [CrossRef]

49. Wangler, T.P. Modelling biocide release from architectural coatings. Chem. Today 2011, 29, 14-16.

50. Wangler, T.P.; Zuleeg, S.; Vonbank, R.; Bester, K.; Boller, M.; Carmeliet, J.; Burkhardt, M. Laboratory scale studies of biocide leaching from facade coatings. Build. Environ. 2012, 54, 168-173. [CrossRef]

51. LeachXS \& ORCHESTRA. Available online: http://cementbarriers.org/partner-codes/leachxs-orchestra/ (accessed on 8 November 2021).

52. Parkhurst, D.L.; Appelo, C.A.J. Description of Input and Examples for PHREEQC Version 3-A Computer Program for Speciation, Batch-Reaction, One-Dimensional Transport, and Inverse Geochemical Calculation. In US Geological Survey Techniques and Methods. Available online: https:/ / pubs.usgs.gov/tm/06/a43/ (accessed on 8 November 2021).

53. Tiruta-Barna, L. Using PHREEQC for modelling and simulation of dynamic leaching tests and scenarios. J. Hazard Mater. 2008, 157, 525-533. [CrossRef]

54. Schiopu, N.; Tiruta-Barna, L.; Jayr, E.; Méhu, J.; Moszkowicz, P. Modelling and simulation of concrete leaching under outdoor exposure conditions. Sci. Total Environ. 2009, 407, 1613-1630. [CrossRef]

55. Vega-Garcia, P.; Schwerd, R.; Schwitalla, C.; Johann, S.; Scherer, C.; Helmreich, B. Leaching prediction for vertical test panels coated with plaster and mortars exposed under real conditions by a PHREEQC leaching model. Chemosphere 2021, 280, 130657. [CrossRef] [PubMed]

56. Vega-Garcia, P.; Schwerd, R.; Scherer, C.; Schwitalla, C.; Helmreich, B. Development of a model for stormwater runoff prediction on vertical test panels coated with plaster and mortar. Water 2020, 12, 2593. [CrossRef]

57. Uhlig, S.; Colson, B.; Schoknecht, U. A mathematical approach for the analysis of data obtained from the monitoring of biocides leached from treated materials exposed to outdoor conditions. Chemosphere 2019, 228, 271-277. [CrossRef]

58. Tietje, O.; Burkhardt, M.; Rohr, M.; Schoknecht, U.; Borho, N. Emissions- und Übertragungsfunktionen für die Modellierung der Auslaugung von Bauprodukten. UBA Texte 28/2018. Available online: https:/ / www.umweltbundesamt.de/publikationen/ emissions-uebertragungsfunktionen-fuer-die (accessed on 8 November 2021).

59. PELMO. Available online: https://esdac.jrc.ec.europa.eu/projects/pelmo (accessed on 8 November 2021).

60. PEARL. Available online: https:/ / esdac.jrc.ec.europa.eu/projects/pearl (accessed on 8 November 2021).

61. Tietje, O. Anwendung von Pedotransferfunktionen für Sorptionsparameter zur Sickerwasserprognose von aus Beregneten Bauteilen Emittierten Substanzen; Fraunhofer IRB Verlag: Stuttgart, Germany, 2017.

62. FEEFLOW. Available online: https:/ / www.mikepoweredbydhi.com/products/feflow (accessed on 8 November 2021).

63. ModFlow. Available online: https://www.usgs.gov/mission-areas/water-resources/science/modflow-and-related-programs? qt-science_center_objects=0\#qt-science_center_objects (accessed on 8 November 2021).

64. IGWMC Home-Integrated Groundwater Modeling Center. Available online: https://igwmc.mines.edu (accessed on 8 November 2021).

65. CEN/TR 17105:2017. Construction Products-Assessment of Release of Dangerous Substances-Guidance on the Use of Ecotoxicity Tests Applied to Construction Products. Available online: https://www.beuth.de/de/technische-regel/din-cen-tr-17 105/275952200 (accessed on 8 November 2021).

66. Heisterkamp, I.; Ratte, M.; Schoknecht, U.; Gartiser, S.; Kalbe, U.; Ilvonen, O. Ecotoxicological evaluation of construction products: Inter-laboratory test with DSLT and percolation test eluates in an aquatic biotest battery. Environ. Sci. Eur. 2021, 33, 75. [CrossRef]

67. Blue Angel. The German Ecolabel. Concrete Products Containing Recycled Aggregates for Outdoor Flooring, Version 1. 2021. Available online: https:/ / www.blauer-engel.de/en/companies/basic-award-criteria (accessed on 8 November 2021).

68. COMLEAM. Available online: https://www.comleam.ch/de (accessed on 8 November 2021).

69. DELPHIN. Available online: http://www.bauklimatik-dresden.de/delphin/index.php (accessed on 8 November 2021).

70. Nicolai, A.; Grunwald, J.; Zhang, J.S. Salztransport und Phasenumwandlung-Modellierung und Numerische Lösung im Simulationsprogramm Delphin 5. Bauphysik 2007, 29, 231-239. [CrossRef]

71. Ytreberg, E.; Lagerström, M.; Nöu, S.; Wiklund, A.-K.E. Environmental risk assessment of using antifouling paints on pleasure crafts in European Union waters. J. Environ. Manag. 2021, 281, 111846. [CrossRef] [PubMed] 
72. Van Zomeren, A.; Dijkstra, J.J.; Susset, B. Technical Principles Underlying Limit Values for Release of Substances for the Percolation Test TS3: Comparison DE and NL. ECN Publication ECN-E-13-059. 2013. Available online: http://resolver.tudelft.nl/uuid: 32739cc0-b45d-4c10-98c1-a142317e7cbc (accessed on 8 November 2021).

73. Burkhardt, M.; Rohr, M.; Tietje, O.; Klingler, M.; Savi, D.; Junghans, M. Emissionsbasierte BauproduktebewertungGewässerschutz an der Quelle: Nachhaltiges Bauen durch Anwendung eines neuen Konzepts. Aqua Gas 2021, 4, 55-64.

74. Burkhardt, M.; Gehring, S.; Rohr, M.; Tietje, O. Auswaschung von Bioziden aus Bauprodukten und Exposition in der UmweltBerechnung von ESD-Szenarien und Modellierung mit der Software COMLEAM, Bericht im Auftrag des Schweizer Bundesamtes für Umwelt (BAFU). 2021. Available online: https:/ / www.umtec.ch/fileadmin/user_upload/umtec.hsr.ch/Projekte/projekte/ 210910_MODCOM_Bericht_final.pdf (accessed on 8 November 2021).

75. Deutsches Institut für Bautechnik (DIBt). Grundsätze zur Bewertung der Auswirkungen von Bauprodukten auf Boden und Grundwasser, Teil I bis III, September 2011, Berlin. Available online: https:/ /www.dibt.de/fileadmin/dibt-website/Dokumente/ Referat/II6/Bauprodukte_Boden_Grundwasser_Grundsaetze_Bewertung.pdf (accessed on 8 November 2021). 